\title{
Feeding Behavior of Captive-Reared Juvenile Alligator Snapping Turtles (Macrochelys temminckii)
}

M. B. East

MSU Graduate Student

B. M. Fillmore

Day B. Ligon

Missouri State University

Follow this and additional works at: https://bearworks.missouristate.edu/articles-cnas

\section{Recommended Citation}

East, Mitchell B., Brian M. Fillmore, and Day B. Ligon. "Feeding Behavior of Captive-Reared Juvenile Alligator Snapping Turtles (Macrochelys temminckii)." Southeastern Naturalist 12, no. 4 (2013): 692-702.

This article or document was made available through BearWorks, the institutional repository of Missouri State University. The work contained in it may be protected by copyright and require permission of the copyright holder for reuse or redistribution.

For more information, please contact BearWorks@library.missouristate.edu. 


\title{
Feeding Behavior of Captive-Reared Juvenile Alligator Snapping Turtles (Macrochelys temminckii)
}

\author{
Mitchell B. East ${ }^{1,3, *}$, Brian M. Fillmore ${ }^{2}$, and Day B. Ligon ${ }^{1}$
}

\begin{abstract}
Feeding preference of Macrochelys temminckii (Alligator Snapping Turtle) is not well known. Juveniles reared with no prior exposure to natural prey were tested for innate prey (i.e., fish) preference and foraging ability for mussels in coarse and fine substrates. Alligator Snapping Turtles consumed fish non-selectively, except that they selected Lepomis macrochirus (Bluegill) over Gambusia affinis (Mosquitofish) in live-prey trials, and Lepomis cyanellus (Green Sunfish) over Notemigonus crysoleucas (Golden Shiners) in carrion trials. Juvenile Alligator Snapping Turtles were less active and less successful when foraging for a benthic prey species, Lampsilis siliquoidea (Fatmucket), in coarse substrate than they were when the mussels were in fine and no substrates. Juvenile Alligator Snapping Turtle preference for Bluegill in a controlled environment corresponds to predator and prey habitat associations but could also be influenced by prey (i.e., fish) behavior. Likewise, enhanced activity and prey encounters in fine substrate are consistent with observations of Alligator Snapping Turtle habitat use.
\end{abstract}

\section{Introduction}

Macrochelys temminckii Troost (Alligator Snapping Turtle) is a top predator in the river basins that drain into the Gulf of Mexico. Adults (Elsey 2006, Iverson and Hudson 2005, Sloan et al. 1996), and juveniles (East 2012) have broad omnivorous diets that include fish, invertebrates, and plant material. Harrel and Stringer (1997) documented the prevalence of Lepomis spp. (sunfish) otoliths in fecal samples of adults from one locality, and suggested that sunfish species were the most frequent prey items because of otolith abundance. The presence of some prey, such as medium-sized mammals, also suggests this species is a scavenger (Elsey 2006). Although the diet of Alligator Snapping Turtles has been documented, feeding behavior has been the subject of just one study that quantified luring success and described luring behavior of captive-born hatchlings (Drummond and Gordon 1979). That study implied that Alligator Snapping Turtles are primarily sit-andwait predators. However, the documented consumption of mussels, other aquatic invertebrates, and various plant materials indicates that this species may sometimes actively forage.

There are no studies that have considered what factors influence Alligator Snapping Turtle capture of fish or active foraging for other food items. Sloan et al. (1996) suggested that observation of wild individuals would be necessary to elucidate feeding behavior further. Although an observation of luring behavior in a wild

\footnotetext{
${ }^{1}$ Biology Department, Missouri State University, 901 South National Avenue, Springfield, MO 65897. ${ }^{2}$ Tishomingo National Fish Hatchery, US Fish and Wildlife Service, 5501 West Highway 7, Tishomingo, OK 73460. ${ }^{3}$ Current address - Natural Heritage New Mexico, University of New Mexico, Albuquerque, NM 87131. *Corresponding author - mitch.east86@ gmail.com.
} 
Alligator Snapping Turtle has been reported (Hiler et al. 2006), this approach is not feasible for study of feeding behavior in many Alligator Snapping Turtle populations because the species is cryptic and its habitat usually includes turbid water that limits visibility. However, further understanding the feeding behavior of Alligator Snapping Turtles can be achieved by observing individuals in a controlled environment, an approach that has been used in studying feeding behavior of other aquatic turtles. For instance, Mahmoud (1968) described factors influencing prey selection of kinosternids and demonstrated the strength of kinosternid sensitivity to olfactory cues in laboratory trials. Burghardt and Hess (1966) demonstrated food imprinting in Chelydra serpentina L. (Snapping Turtle) and suggested the likelihood of consuming novel foods would decrease with exposure to imprinted food.

We investigated whether naïve juvenile Alligator Snapping Turtles: 1) select live fish species at random, or if certain prey species are more likely to be captured and consumed, 2) preferentially select certain fish species when they are offered as carrion, and 3) exhibit variable foraging success on freshwater mollusks on different substrates. Based on a previous report of their prevalence in Alligator Snapping Turtle diet (Harrel and Stringer 1997), we predicted that juveniles would capture and consume sunfish species more frequently than alternatives. We also predicted that when the same prey species were offered as carrion, juveniles would consume more prey than when offered live fish, and that selection of carrion would be independent of prey species. Finally, we predicted that juvenile Alligator Snapping Turtle consumption of Lampsilis siliquoidea Barnes (Fatmucket) and foraging activity would increase in the presence of substrate because substrate is expected to stimulate searching behavior.

\section{Methods}

Our study focused on the behavior of juvenile Alligator Snapping Turtles destined to be released as part of a reintroduction program. These turtles are produced by brood stock at Tishomingo National Fish Hatchery (TNFH). Each year, eggs are collected from nests laid at the hatchery and incubated at $27.5-28.5^{\circ} \mathrm{C}$ (Ligon and Lovern 2009). Hatchlings are reared indoors and subsist on commercially produced pellets for 2-3 years. Prior to reintroduction, individuals are typically stocked in an outdoor pond for 9-12 months for acclimatization and to increase experience foraging for non-pelleted foods. By observing juvenile feeding behavior prior to outdoor acclimatization, we were able to test for the presence of innate prey-capture success and prey preference.

All feeding trials were conducted at TNFH in a controlled environment. Turtles were maintained in communal tanks connected to a continuous supply of creek water and fed a diet of commercial pellets. Turtles were fasted in groups for 4 days prior to each feeding trial and then separated into individual tanks the day on which they were tested. Morphometrics (midline carapace-length and mass) were recorded for each turtle before feeding trials began. Individuals were allowed to acclimate to the new tank for one hour before prey was offered. All live-prey fish trials and substrate trials were monitored and recorded using a video surveillance system equipped with infrared lights (SVAT Electronics, Cheektowaga, NY). 


\section{Prey-selection trials}

Turtles from the 2008 year-class were used in the study, and ranged from 118.6-150.1 mm straight midline carapace-length $($ mean $=123.71 \mathrm{~mm})$. The fish offered were: Lepomis macrochirus Rafinesque (Bluegill), Notemigonus crysoleucas Rafinesque (Golden Shiner), Lepomis cyanellus Rafinesque (Green Sunfish), and Gambusia affinis Baird and Girard (Mosquitofish). These fish species were used because they are probable, if not documented, prey and were readily available at TNFH. All fish were collected from hatchery ponds that had been drained as part of routine hatchery operations or were removed from hatchery ponds using baited minnow traps and cast nets. Size of Bluegill and Green Sunfish offered was restricted to small juvenile, young-of-year fish; the size of Golden Shiners and Mosquitofish was not controlled. Fish species were offered in pairs (10 fish of each species offered simultaneously) with each species pair, hereafter referred to as a dyad. The two sunfish species were not tested against each other because of an a priori assumption that congeneric prey would not be differentially consumed.

We separated turtles into individual $1-\mathrm{m}^{2}$ square plastic tanks with $\approx 60$-cm-high walls filled with water to a level of $20 \mathrm{~cm}$. Individual turtles were tested only once and live-prey dyads were tested 5 times ( $n=25$ trials). We marked turtles with PIT tags and assigned each turtle to dyads and trials. The trials were repeated with fish as carrion using 25 untested turtles (fish were less than one month old, frozen and thawed prior to trials) except for the Bluegill-Golden Shiner dyad which was tested in 4 trials, and the Bluegill-Mosquitofish dyad which underwent 6 trials (carrion trials, $n=25$ ). We recorded the total mass for each species before adding them to trial tanks. Mass of live fish was measured collectively rather than individually to reduce handling stress and avoid influencing their likelihood of being consumed. Trials began once fish were added to trial tanks and continued for 6 hours. After each 6-hour trial, we recorded the number of each remaining fish species.

\section{Substrate trials}

We tested fifteen turtles from the 2009 year-class (mean midline carapace-length $=96.3 \mathrm{~mm}$, range $=89.0-103.3 \mathrm{~mm}$ ) for the ability to identify and consume a single mussel size-class (total length $=1.0-1.9 \mathrm{~cm}$ ) in three substrate treatments: no substrate, fine, and coarse. Fine substrate was sand-sized particles (particles were $>0.225 \mathrm{~mm}$ and $<1 \mathrm{~mm}$ ), and coarse substrate consisted of gravel (mean diameter $=$ $9.13 \mathrm{~mm}$ ) from a nearby stream ( $n=15$ trials, with 5 trials for each treatment). All mussels, Fatmuckets, were obtained from the mussel propagation lab at Missouri State University (Springfield, MO). This common mussel species is sympatric with Alligator Snapping Turtles and is a presumed prey species. Substrate was contained in a 1.5 -cm-deep tray and mussels were allowed 1 hour to settle into the substrate before trials began. Each 24-hour trial was conducted in 1.2-m by 0.4-m rectangular fiberglass tanks with $\approx 25$-cm-high walls filled with water to a depth of $10 \mathrm{~cm}$.

Twenty mussels were offered in each trial. After each 24-hour trial, we recorded the number of remaining mussels. We observed video from substrate trials after the completion of all trials and the behavior of each turtle was quantified. 
We measured and recorded the following variables for each trial: number of encounters with prey, number of feeding attempts, and number of mussels consumed. Encounters were defined as events in which turtles actively foraged with their snout to the substrate, initiated contact with mussels, or were engaged in digging with their feet while their snouts were lowered to the substrate. Turtles engaged in this behavior were assumed to be foraging and recognizing mussels as a potential food source. We classified feeding attempts as those events in which turtles handled mussels or attempted to crush and ingest mussels.

\section{Data analysis}

We tested all data for normality before performing statistical tests, and used nonparametric tests when appropriate. Results of prey-selection trials were summarized in two-way tables for each dyad and analyzed by Fisher's exact test of independence because of small sample sizes. We used the normal approximation test for two proportions to compare the proportion of fish trials resulting in consumption of prey in live and carrion trials. Also, we used the same test to compare the number of fish consumed as a proportion of the total available between live and carrion trials. We compared the number of encounters between juvenile turtles and mussels during substrate trials across treatment groups using one-way ANOVA. The number of feeding attempts was compared across treatment groups using the Kruskal-Wallis test. We also analyzed the correlation between the number of encounters and predation attempts using Pearson correlation analysis. All statistical tests were performed with Minitab ${ }^{\circledR}$ Statistical Software $(\alpha=0.05)$.

\section{Results}

\section{Prey-selection trials}

Sixteen of 25 (64\%) live-prey dyads resulted in the capture and consumption of at least one fish (Table 1). The Green Sunfish-Mosquitofish, Golden ShinerMosquitofish, and Golden Shiner-Bluegill dyads exhibited no significant difference in prey consumption by juvenile Alligator Snapping Turtles. Golden Shiners and Green Sunfish were preyed upon equally when they were presented to the juvenile turtles at the same time $(P=0.11)$. Only in the Bluegill-Mosquitofish dyad did differences in prey consumption approach significance, suggesting that prey capture was not independent of species; Bluegill were consumed more frequently than Mosquitofish $(P=0.06)$.

Table 1. Results of captive-reared juvenile Macrochelys temminckii (Alligator Snapping Turtle) feeding trials on representative live-prey fish species ( $n=$ number of trials in which feeding occurred).

\begin{tabular}{llcccc} 
& & \multicolumn{2}{c}{ Number consumed } & Fisher's Exact \\
\cline { 3 - 4 } Arena (species I vs. II) & $n$ & Species I & Species II & $P$-value \\
\hline Golden Shiner vs. Bluegill & 3 & 4 & 8 & 0.36 \\
Mosquitofish vs. Bluegill & 3 & 1 & 7 & 0.06 \\
Golden Shiner vs. Mosquitofish & 2 & 3 & 1 & 0.62 \\
Green Sunfish vs. Mosquitofish & 4 & 1 & 3 & 0.62 \\
Golden Shiner vs. Green Sunfish & 4 & 6 & 1 & 0.11 \\
\hline
\end{tabular}


Fish were consumed in 20 of $25(80 \%)$ carrion dyads. The proportion of these dyads resulting in consumption of prey was not significantly different from that of live-prey dyads $(P=0.20)$. However, the number of fish consumed as a proportion of the total number offered was significantly greater in carrion dyads than it was in live-prey dyads $(P=0.02)$. When offered as carrion, Bluegill and Golden Shiners were consumed with equal frequency (Table 2). In Bluegill-Mosquitofish carrion trials, frequency of consumption of Bluegill over Mosquitofish occurred at a nearly significant level $(P=0.08)$. Mosquitofish and Golden Shiners were consumed with the same frequency when presented together. Consumption of Green Sunfish was not significantly different than that of Mosquitofish when the species were offered as carrion $(P=0.20)$. Finally, Green Sunfish were significantly more likely to be consumed as carrion than Golden Shiners when the two species were offered simultaneously $(P=0.02)$.

\section{Substrate trials}

Feeding occurred in 5 of 15 (33\%) substrate trials featuring juvenile Fatmucket as prey; ingestion of prey occurred in three trials with no substrate and two trials with fine substrate. We observed marginal significant differences in number of encounters when substrate treatments were compared (ANOVA: $F_{2,12}=3.03, P=$ 0.09). The mean number of encounters for each substrate treatment shows that Alligator Snapping Turtles are more likely to encounter mussels in fine substrate and in treatments with no substrate (Fig. 1A). Comparison of feeding attempts showed similar trends, but there was no significant difference among treatments (Kruskal-Wallis test: $\mathrm{H}_{2,12}=1.43, P=0.49$; Fig. 1B). There was a correlation between feeding attempts and number of encounters $(r=0.62, P=0.01)$ indicating that $62.0 \%$ of the variation in feeding attempts was due to number of encounters.

\section{Discussion}

\section{Prey-selection trials}

Green Sunfish were consumed more frequently than Golden Shiners in the carrion dyad but there was no statistical difference in this live-prey dyad. This result suggests that juvenile Alligator Snapping Turtles could have a preference for Green Sunfish over Golden Shiners, but prey behavior likely influences capture success. In contrast, in Mosquitofish-Bluegill dyads, Bluegill were consumed

Table 2. Results of captive-reared juvenile Macrochelys temminckii (Alligator Snapping Turtle) feeding trials on representative carrion prey fish species $(n=$ number of trials in which feeding occurred).

\begin{tabular}{lcccc} 
& & \multicolumn{2}{c}{ Number consumed } & Fisher's Exact \\
\cline { 3 - 4 } Arena (species I vs. II) & $n$ & Species I & Species II & $P$-value \\
\hline Golden Shiner vs. Bluegill & 4 & 5 & 6 & 1.00 \\
Mosquitofish vs. Bluegill & 5 & 3 & 10 & 0.08 \\
Golden Shiner vs. Mosquitofish & 2 & 1 & 1 & 1.00 \\
Green Sunfish vs. Mosquitofish & 4 & 3 & 8 & 0.20 \\
Golden Shiner vs. Green Sunfish & 5 & 5 & 15 & 0.02 \\
\hline
\end{tabular}




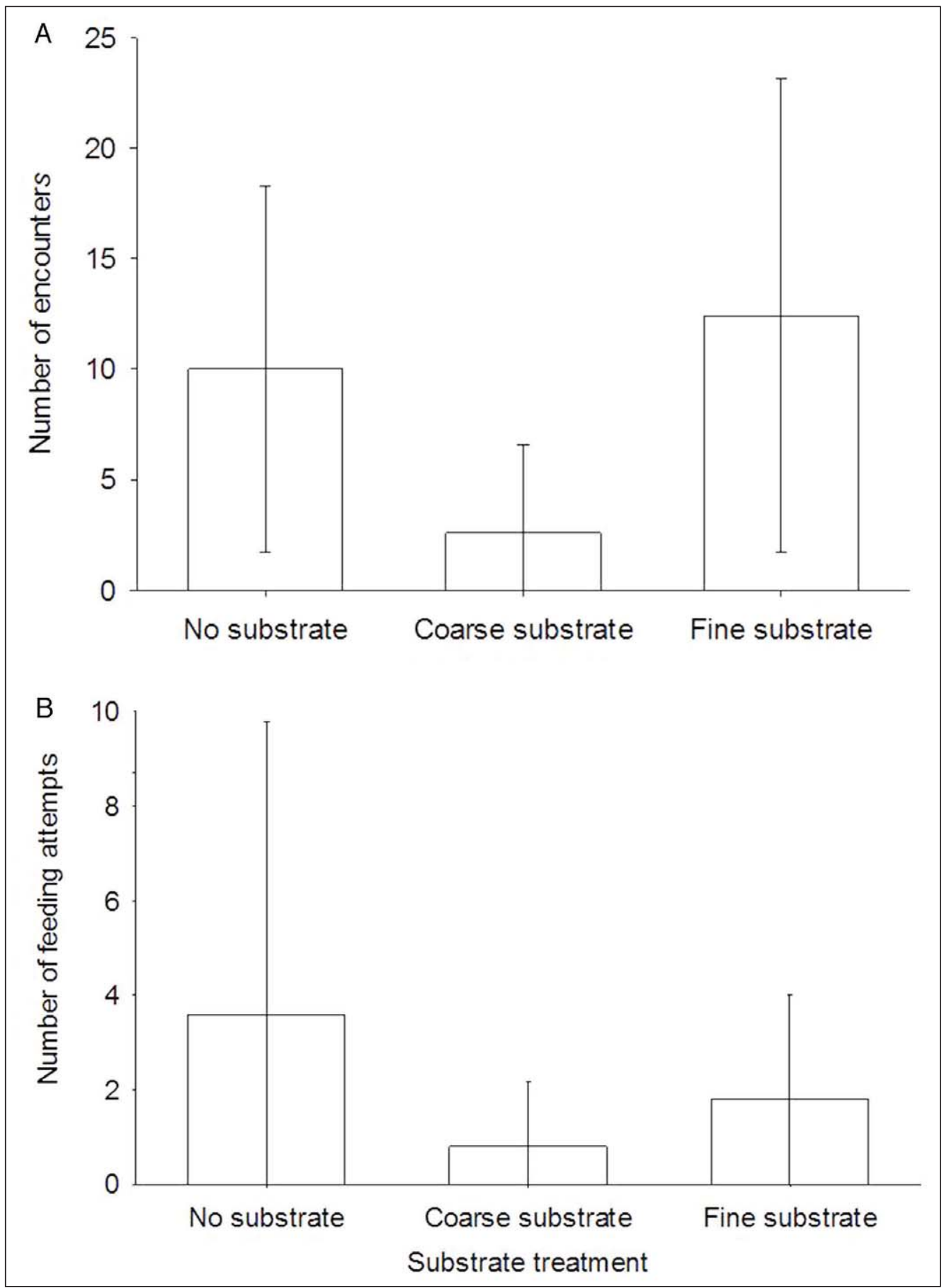

Figure 1. Mean and 95\% confidence intervals for A) number of encounters of Macrochelys temminckii (Alligator Snapping Turtle) with mollusk prey for each substrate treatment (one-way ANOVA: $F_{2,12}=3.03, P=0.09$ ); and B) number of feeding attempts by Alligator Snapping Turtle on mollusk prey for each substrate treatment (Kruskal-Wallis test: $H_{2,12}=$ $1.43, P=0.49)$. 
more frequently at nearly significant levels than Mosquitofish in live and carrion dyads. There are several potential explanations for these preferences. For example, sunfishes and Alligator Snapping Turtles often inhabit very similar microhabitats. Laboratory observations have indicated that Bluegill favor lowlight habitat (Johnson 1993), and field observations have demonstrated Bluegill preference for dense structures such as brush piles (Johnson and Lynch 1992). Golden Shiners typically occupy weedy areas of the littoral zone by day and move to deeper water at night (Keast and Webb 1966), whereas Mosquitofish tend to prefer submerged cover and calm water (Casterlin and Reynolds 1977). Alligator Snapping Turtles exhibit preferences for submerged structures and sites with riparian canopy cover (Harrel et al. 1996, Riedle et al. 2006). When trapping Alligator Snapping Turtles as part of another study, we observed that sunfish were the most abundant fish by-catch, though the mesh size of traps used would have precluded capture of smaller fishes (East 2012). These habitat associations may explain why Harrel and Stringer (1997) detected a high relative frequency of sunfish in the diet of wild Alligator Snapping Turtles.

Though there were few differences in consumption of live prey, fish behavior likely played a role in the trials because live prey were less frequently consumed than fish in carrion trials. The influence of conspecific chemical cues released after attacks and successful predation can influence fish behavior and decrease the probability of their capture. For example, fish responses to chemical alarm cues released by depredated conspecifics and sympatric guild members include avoidance behavior in order to decrease predation risk (Chivers and Smith 1994, Marcus and Brown 2003). Drummond and Gordon (1979) reported that in hatchling Alligator Snapping Turtle feeding trials, Mosquitofish retreated to the corner of the tank and remained motionless after turtles fed successfully on other Mosquitofish. While live-prey trials are most likely influenced by the evasive behaviors of the various species offered, our results showed a higher likelihood of Alligator Snapping Turtles feeding on Bluegill in one live-prey dyad and no difference in the other dyads.

Carrion trials removed the influence of prey behavior and also indicated a higher likelihood for consumption of sunfish in two dyads. One explanation for the higher observed likelihood of sunfish selection in carrion arenas is that the average sunfish mass was higher than those of Mosquitofish and Golden Shiners (Table 3). According to optimal foraging theory, consumers select food items that yield the highest net energy intake, provided they are available (MacArthur and

Table 3. Mean mass (g) of each fish species used in live and carrion feeding trials.

\begin{tabular}{lcc} 
Prey species & $\begin{array}{c}\text { Mean total fish mass } \\
\text { in live trials }( \pm \text { SE) }\end{array}$ & $\begin{array}{c}\text { Mean total fish mass } \\
\text { in carrion trials }( \pm \text { SE) }\end{array}$ \\
\hline Bluegill & $35.0( \pm 9.7)$ & $52.0( \pm 9.0)$ \\
Green Sunfish & $42.4( \pm 5.3)$ & $44.0( \pm 2.0)$ \\
Golden Shiner & $31.9( \pm 1.9)$ & $28.9( \pm 2.5)$ \\
Mosquitofish & $10.2( \pm 0.3)$ & $9.6( \pm 0.3)$ \\
\hline
\end{tabular}


Pianka 1966, Pyke 1984). However, mean Mosquitofish mass was lower than mean Golden Shiner mass, and prey preference was not evident in this dyad. Irons et al. (1986) observed experimental prey-preference of Papilio glaucus L. (Glaucouswinged Gull) that differed from prey selection under natural conditions. Though not directly addressed in this study, these observations could indicate that juvenile Alligator Snapping Turtles exhibit a prey preference for sunfish species that is not based strictly on size.

Carrion trials more frequently resulted in the consumption of fish offered to individual turtles and indicated that opportunistic scavenging may be an important source of meals for reintroduced juveniles. Many of the larger vertebrates in the diet of Alligator Snapping Turtles (Elsey 2006, Sloan et al. 1996) are probably consumed in this manner, although live capture of larger prey is also possible. The opportunistic feeding behavior of the species explains foraging for carrion despite the obvious morphological specializations that support sedentary, sit-and-wait predatory behavior. Sloan et al. (1996) suggested that sedentary adults rely less on active foraging and more on luring. However, other authors have suggested that the lingual lure, which is most colorful in juveniles, might lose its usefulness for older individuals as the lure undergoes melanism (Ewert et al. 2006, Pritchard 1989). The results of this study lead to the conclusion that prey capture success is not heavily influenced by preference for a single prey species and that naïve, head-started juvenile Alligator Snapping Turtles may opportunistically forage to maximize energy intake.

\section{Substrate trials}

Juvenile Alligator Snapping Turtle foraging encounters varied among treatments. Encounters with mussels in fine substrate were most often associated with digging behavior that was initiated upon contact with the substrate, and such behavior was less frequent in the presence of coarse substrate. Trials in which there was no substrate resulted in an encounter frequency equal to that of the fine substrate treatment trials. Therefore, we conclude that foraging activity and recognition of mussels as a food source could be inhibited in coarse substrate types.

Feeding attempts were observed in many trials but successful ingestion of mussels was rare. This result might be explained by lack of experience with a superficially unpalatable prey. Additionally, mussels that were active and siphoning might have been more attractive prey because they were exposing more soft tissue. The number of feeding attempts correlated with the number of encounters and further suggests a lack of experience as the cause of low feeding success. Attempts to feed were frequent relative to the frequency of ingestion, which was observed in few trials. Since many turtles frequently encountered and attempted to feed on mussels, but failed to successfully feed, we conclude that the lack of experience was the probable cause of low ingestion rates.

With the evident correlation between encounter rates and feeding attempts, the results imply that Alligator Snapping Turtle foraging for benthic prey could be more successful when prey are located in fine substrate. Also, active foraging 
would increase the frequency with which individuals encounter carrion and other food types lying exposed in stream or lake beds. Field observations and studies of the diet of wild individuals support this conclusion; mussels and other invertebrates found in benthic environments are frequently found in the diet of juveniles (East 2012) and adults (Elsey 2006, Sloan et al. 1996). Furthermore, one researcher observed adult Alligator Snapping Turtles engaged in apparent active foraging at night that included moving along the bottom of a stream with their snout lowered to the substrate presumably in search of food by chemical cues (unpublished observations in Ewert et al. 2006).

The association between Alligator Snapping Turtles, fine substrate types, and detritus has also been documented in wild populations (Lescher 2010, Riedle 2001). These observers found Alligator Snapping Turtles in microhabitats that would be expected to contain many benthic diet items such as mussels, macroinvertebrates, and fallen riparian vegetation. Although it has not been described in Alligator Snapping Turtles specifically, Moll and Moll (2000) described a feeding behavior, "benthic bulldozing", in which some foraging river turtles ingest detritus and prey along the benthos haphazardly. Smaller-order streams and many rivers that are lined with abundant riparian vegetation accumulate fallen plant materials in the benthos. These lower-order streams often harbor benthic macroinvertebrates that rely upon these allochthonous sources of energy (Allan and Castillo 2007). This behavior is a potential explanation for the incidence of macroinvertebrates in the diet of some Alligator Snapping Turtles and the presence of detritus that is commonly found in diet samples of Alligator Snapping Turtles (East 2012, Elsey 2006, Sloan et al. 1996).

\section{Summary}

Burghardt and Hess (1966) demonstrated that hatchling Snapping Turtles imprint on food and suggested that imprinting could significantly lower the probability that individuals would feed upon alternative food items. The animals we tested had experienced prolonged exposure to a single food item (pellet feed) and had no exposure to alternative food sources. The high probability of individuals to consume fish, high foraging encounter rates, and frequent feeding attempts in our feeding trials indicate that instinctual feeding behaviors in captive-reared juvenile Alligator Snapping Turtles allow for successful foraging for active and passive prey despite inexperience.

Our results indicate that naïve juveniles are somewhat successful at capturing live prey. However, it is important to note that such a specialization does not indicate that Alligator Snapping Turtles are dietary specialists. This finding is noteworthy because successful reintroduction of this species will depend on the ability of head-started juveniles to forage successfully. The results of our study indicate that capture of live prey is mostly independent of prey species but likely is influenced by biotic and abiotic factors. Finally, released juveniles probably consume carrion and non-fish food items located by active or opportunistic foraging, while fishing success could increase with experience. 


\section{Acknowledgments}

We would like to thank the staff at Tishomingo National Fish Hatchery for providing support and use of their facilities. This project was funded by the Missouri State University Graduate College and Biology Department and a Sigma Xi Grant-in-Aid of Research to M.B. East. The work was conducted with the approval of the Missouri State University Animal Care and Use Committee (Protocol \# 11025).

\section{Literature Cited}

Allan, J.D., and M.M. Castillo. 2007. Stream ecosystem metabolism. Pp. 287-315, In Stream Ecology: Structure and Function of Running Waters, $2^{\text {nd }}$ Edition. Springer Science, Dordrecht, The Netherlands. 436 pp.

Burghardt, G.M., and E.H. Hess. 1966. Food imprinting in the turtle, Chelydra serpentina. Science 151:108-109.

Casterlin, M.E., and W.W. Reynolds. 1977. Aspects of habitat selection in the Mosquitofish, Gambusia affinis. Hydrobiologia 55:125-127.

Chivers, D.P., and J.F. Smith. 1994. Intra- and interspecific avoidance of areas marked with skin extract from Brook Sticklebacks (Culea inconstans) in a natural habitat. Journal of Chemical Ecology 20:1517-1524.

Drummond, H., and E.R. Gordon. 1979. Luring in the neonate Alligator Snapping Turtle (Macroclemys temminckii): Description and experimental analysis. Zietschrift fur Tierpsychologie 50:136-152.

East, M.B. 2012. Diet and feeding behavior of juvenile Alligator Snapping Turtles (Macrochelys temminckii) in eastern Oklahoma. M.Sc. Thesis. Missouri State University, Springfield, MO. $86 \mathrm{pp}$.

Elsey, R.M. 2006. Food habits of Macrochelys temminckii (Alligator Snapping Turtle) from Arkansas and Louisiana. Southeastern Naturalist 5(3):443-452.

Ewert, M.A., D.R. Jackson, and P.E. Moler. 2006. Macrochelys temminckii-Alligator Snapping Turtle. Chelonian Research Monographs 3:58-71.

Harrel, J.B., and G.L. Stringer. 1997. Feeding habits of the Alligator Snapping Turtle (Macroclemys temminckii) as indicated by teleostean otoliths. Herpetological Review 28:185-187.

Harrel, J.B., C.M. Allen, and S. Hebert. 1996. Movements and habitat use of subadult Alligator Snapping Turtles (Macroclemys temminckii) in Louisiana. American Midland Naturalist 135(1):60-67.

Hiler, W.R., B.A. Wheeler, and S.E. Trauth. 2006. Macrochelys temminckii (Alligator Snapping Turtle): Feeding behavior. Herpetological Review 37:217.

Irons, D.B., R.G. Anthony, and J.A. Estes. 1986. Foraging strategies of Glaucous-Winged Gulls in a rocky intertidal community. Ecology 67:1460-1474.

Iverson, J.B., and R. Hudson. 2005. Macrochelys temminckii (Alligator Snapping Turtle): Diet. Herpetological Review 36:312-313.

Johnson, D.L., and W.E. Lynch, Jr. 1992. Panfish use of and angler success at evergreen tree, brush, and stake-bed structures. North American Journal of Fisheries Management 12:222-229.

Johnson, S.L. 1993. Cover choice by Bluegills: Orientation of underwater structure and light intensity. Transactions of the American Fisheries Society 122:148-150.

Keast, A., and D. Webb. 1966. Mouth and body form relative to feeding ecology in the fish fauna in a small lake. Journal of the Fisheries Research Board of Canada 23:1845-1874. 
Lescher, T.C. 2010. Relative abundance, population structure, and habitat utilization of the Alligator Snapping Turtle (Macrochelys temminckii) and Eastern Snapping Turtle (Chelydra serpentina) in southeastern Missouri. M.Sc. Thesis. University of Missouri-Saint Louis, St. Louis, MO. 75 pp.

Ligon, D.B., and M.B. Lovern. 2009. Temperature effects during early life stages of the Alligator Snapping Turtle (Macrochelys temminckii). Chelonian Conservation and Biology 8(1):74-83.

MacArthur, R.H., and E.R. Pianka. 1966. On the optimal use of a patchy environment. The American Naturalist 100:603-609.

Mahmoud, I.Y. 1968. Feeding behavior in kinosternid turtles. Herpetologica 24:300-305.

Marcus, J.P., and G.E. Brown. 2003. Response of Pumpkinseed Sunfish to conspecific chemical alarm cues: An interaction between ontogeny and stimulus concentration. Canadian Journal of Zoology 81:1671-1677.

Moll, E.O., and D. Moll. 2000. Conservation of river turtles. Pp. 126-155 In M.W. Klemens (Ed.). Turtle Conservation. Smithsonian Institution Press, Washington, DC. 344 pp.

Pritchard, P.C.H. 1989. The Alligator Snapping Turtle: Biology and Conservation. Milwaukee Public Museum, WI. 152 pp.

Pyke, G.H. 1984. Optimal foraging theory: A critical review. Annual Review of Ecology and Systematics 15:525-573.

Riedle, J.D. 2001. The ecology of the Alligator Snapping Turtle, Macrochelys temminckii, in Oklahoma. M.Sc. Thesis. Oklahoma State University, Stillwater, OK. 130 pp.

Riedle, J.D., P.A. Shipman, S.F. Fox, and D.M. Leslie, Jr. 2006. Microhabitat use, homerange, and movements of the Alligator Snapping Turtle, Macrochelys temminckii, in Oklahoma. Southwestern Naturalist 51:35-40.

Sloan, K.N., K.A. Buhlmann, and J.E. Lovich. 1996. Stomach contents of commercially harvested adult Alligator Snapping Turtles, Macroclemys temminckii. Chelonian Conservation and Biology 2:96-99. 